\title{
Menjadi Lelaki Sejati : Maskulinitas Dalam Komik Daring Webtoon Indonesia
}

\author{
ASEP WAWAN JATNIKA ${ }^{1}$ \& FERRY FAUZI HERMAWAN ${ }^{2}$ \\ Kelompok Keahlian Ilmu Kemanusiaan Fakultas Seni Rupa dan Desain Institut Teknologi Bandung \\ Gedung labtek 7 Lantai 1 Jl. Ganesha 10 Kota Bandung 40132 Jawa Barat \\ E-mail : aswan_jatmika@yahoo.com,ferryfauzihermawan@itb.ac.id
}

\begin{abstract}
Perkembangan teknologi telah mengubah cara penyebaran komik di Indonesia. Saat ini internet dan media sosial menjadi salah satu media utama penyebaran komik. Salah satu media yang menjadi pilihan tempat menyebarkan dan membaca komik adalah Webtoon. Tulisan ini bermaksud menganalisis wacana homo seksualitas dan maskulinitas yang terdapat dalam komik No Homo karya Apitnobaka yang diterbikan dalam Webtoon. Menggunakan pemahaman Foucault dan Bartkly tentang panoptikon dan gender hasil kajian menunjukkan bahwa pembicaraan masyarakat (gosip) merupakan alat utama dalam pengonstruksian gender di masyarakat. Gosip berperan sebagai pengawas perilaku seperti apa yang boleh dilakukan laki-laki dan sebaliknya. Gosip berperan sebagai panoptikon dalam mengawasi pelanggengan konstruksi maskulinitas di masyarakat. Selain itu, ditemukan juga salah satu penanda maskulinitas ideal di masyarakat yaitu, laki-laki harus menjadi seorang alfa dan tidak bergantung pada orang lain. Jika seorang laki-laki tidak mampu memenuhi hal tersebut dirinya akan digolongkan bukan laki-laki ideal. Dalam komik No Homo dipandang memiliki orientasi seksual lain yaitu homoseksual yang dianggap tabu dalam masyarakat. Selain itu, komik No Homo merefleksikan dan melanggengkan anggapan bahwa orientasi seksual yang bukan hetero seperti homo seksual bukanlah berasal dari Indonesia. Hal itu dipandang sebagai bagian dari budaya Barat.
\end{abstract}

Kata kunci : komik, homoseksual, maskulinitas, panoptikon, laki-laki

\section{To Be Manly : Masculinity In Webtoon Online Comics Indonesia}

Technological developments have changed the way in which comics are circulated and distributed throughout Indonesia. Currently the internet and social media have become the primary media for the distribution of comics. One of the media that has been chosen for circulation, distribution and consumption of comics is Webtoon. This paper intends to analyze discourse in subjects such as homosexuality and masculinity as can be observed in Apitnobaka's No Homo comic as published on Webtoon. Using Foucault's and Bartkly's understanding of the panopticon and the gender; this study suggests that community talk (gossip) plays a major role in gender-building in society. Gossip serves as a supervisory behaviour that shapes gender norms in society i.e., what is considered as acceptable behaviour by a male or vice versa. Gossip serves as a panopticon in overseeing the construction of masculinity in consumer society. Moreover, it can be observed that one of the markers of ideal masculinity in the community is that a male must be an alpha and does not rely on the others can be found within this comic. If a male does not capably fulfil these terms, he will consequently be classified a as non-ideal man by consumer society. In No Homo comics, the male is portrayed as being of homosexual orientation and it is considered as taboo in society. In addition, No Homo comics reflect upon and perpetuate the assumption that sexual orientation other than heterosexual such as a homosexual is apart from Indonesian heteronormative culture. However, it is viewed as being a symptom of western culture.

Keywords : comic, homosexual, masculinity, panopticon, male

Peer Review : 2 - 19 Januari 2018, Acepted to Publish 22 Januari 2018 


\section{PENDAHULUAN}

Perkembangan dan penyebaran karya seni di Indonesia tidak dapat dilepaskan dari keberadaan media massa. Selain penerbit konvensional, media massa menjadi salah satu wadah para seniman untuk mengekspresikan dan menyebarluaskan karya. Hal ini juga berlaku pada seni komik. Salah satu cikal bakal komik Indonesia, Put On, diterbitkan dalam koran yang dikelola oleh para Cina peranakan yaitu Sin Po ketika era kolonial (Bonneff, 1998).

Hubungan erat antara seniman komik dan media massa berlanjut hingga era kemerdekaan. Banyak para seniman komik memilih terlebih dahulu menerbitkan karyanya dalam media massa sebelum diterbitkan menjadi buku. Sama seperti karya sastra, komik yang diterbitkan dalam media massa dapat menjadi sarana komikus untuk mengenalkan karyanya kepada pasar dan meraih popularitas. Beberapa komik muncul setiap hari dalam lembaran koran tetapi banyak di antaranya muncul pada lembaran akhir pekan bersama berita seni yang lain.

Saat ini melalui perkembangan teknologi yang semakin massif menyebabkan medium penyebaran komik menjadi makin meluas. Para komikus tidak hanya dapat memanfaatkan penerbitan konvensional, seperti penerbit cetak dan koran, tetapi juga dapat menggunakan media digital sebagai saluran ekspresi karya. Salah satu media digital yang populer dijadikan tempat menerbitkan komik adalah LINE Webtoon. Line Webtoon merupakan salah satu platform penerbitan digital yang dapat diakses baik melalui web maupun telepon seluler secara daring (dalam jaringan). Menariknya, media ini tidak hanya memfokuskan diri pada penerbitan komikus profesional tetapi juga pada mereka yang baru berkecimpung dalam dunia komik.

Dirilis pada tahun 2015 Indonesia menjadi salah satu pembaca Webtoon terbesar di dunia (Agnes, 2016). Selain itu, keberadaan aplikasi ini telah mengubah cara membaca komik di Indonesia. Para pembaca kini dapat membaca komik melalui aplikasi yang terdapat di dalam telepon selulernya. Jika sebelumnya membaca komik memerlukan intensitas khusus dari pembacanya, seperti sengaja membeli komik atau membaca pada momen tertentu, melalui aplikasi Webtoon pembaca dapat membaca komik terbaru kapan saja dan di mana saja. Selain itu, jika sebelumnya pembaca harus menunggu kelanjutan seri terbaru dari penerbit, saat ini pembaca cukup duduk dengan tenang karena aplikasi Webtoon akan memberi informasi ke dalam telepon seluler tentang kemunculan komik seri terbaru setiap minggu.
Hingga saat ini ada sekitar 36 judul karya webtoonist (komikus webtoon) Indonesia yang dibaca dengan setia oleh jutaan orang (Agnes, 2016). Setidaknya ada sekitar 3 juta pengguna yang membaca Webtoon setiap bulan dan telah diunduh 1,5 juta kali melalui aplikasi seluler (Marketeers Editor, 2015). Karyakarya para komikus Indonesia di Webtoon ini memiliki beragam genre baik komedi, romance, fantasi, $s c i-f i$ maupun horor. Walaupun begitu, genre komik yang paling banyak diminati pembaca Indonesia adalah romance dan komedi. Salah satu komik komedi menarik yang muncul di Webtoon adalah komik yang berjudul No Homo karya Apitnobaka Komik No Homo menceritakan persahabatan dua orang laki-laki bernama Brian dan Ditya yang demikian erat. Oleh karena itu, dua orang ini dipandang memiliki orientasi seksual non-hetero karena sering menghabiskan waktu bersama. Padahal Brian dan Ditya sendiri bukan penyuka sesama jenis (homo seksual). Komik ini menjadi menarik karena mengusung tema yang masih dianggap tabu dalam masyarakat Indonesia yaitu permasalahan homoseksualitas dan konstruksi gender dalam masyarakat. Oleh karena itu, tulisan ini bermaksud melakukan analisis terhadap konstruksi gender dan stereotipe homoseksualitas di masyarakat yang terefleksikan dalam komik No Homo karya Apitnobaka. Selain itu, dibandingkan yang lain komik $N o$ Homo memiliki tingkat keterbacaan yang tinggi. Pelanggan komik ini mencapai 1.926.000 dengan rating 8.93. Apitnobaka juga merupakan salah satu komikus yang berasal dari Indonesia yang mampu bersaing dengan komikus luar negeri yang ada di Webtoon.

Dalam konteks industri komik Amerika, Palmer-Mehhta \& Hay (2005) mengemukakan bahwa masih sedikit para akademisi yang membahas permasalahan seksualitas dalam komik, khususnya yang terkait dengan maskulinitas. Di Indonesia, analisis antara seksualitas, gender, dan komik masih belum banyak dilakukan. Terbaru adalah analisis yang dilakukan oleh Wibowo (2015) dalam buku Si Jampang Jago Betawi; Kajian Tokoh dalam Komik Ganes TH yang membahas maskulinitas dalam karya-karya Ganes TH. Oleh karena itu, tulisan ini diharapkan dapat memenuhi ruang kosong dalam kajian komik di Indonesia khususnya yang berkaitan antara gender dan seksualitas. Berikutnya akan dipaparkan mengenai metode dan landasan teori penelitian.

\section{METODE}

Perkembangan kajian gender dan studi kultural telah memberikan gambaran bagaimana sistem gender dan keberadaan kaum minoritas dalam masyarakat terrefleksikan dalam komik. Hal ini misalnya dapat dilihat melalui penelitian yang dilakukan oleh Glascock \& Preston-schreck (2004) yang menganalisis 
komik-komik yang muncul dalam media massa di Amerika. Dari 1077 karakter yang muncul dari sampel komik 61 persen merupakan karakter laki-laki, 28\% merupakan karakter perempuan, dan 11\% merupakan karakter binatang. Walaupun terdapat peningkatan kemunculan jumlah karakter perempuan menurut Glascock dan Preston-Schreck justru terjadi pengabadian stereotip gender perempuan. Hal tersebut dapat dilihat pada karakter perempuan yang masih berada di bawah bayang-bayang laki-laki (pelengkap penceritaan), kemunculan tokoh perempuan yang hanya terbatas sebagai pekerja domestik dan pengasuh anak, hingga ketidakmampuan perempuan untuk menjaga dirinya sendiri.

Billman (2006) mengemukakan bahwa salah satu penanda penting konstruksi hegemoni tersebut adalah tubuh. Menurutnya tubuh tidak lagi menjadi situs pembuatan budaya tetapi tubuh menjadi tempat budaya tersebut diterapkan. Hal ini misalnya dapat dilihat pada kasus banyaknya lelaki gay yang berhasrat untuk memiliki tubuh atletis dan berotot. Bilman memaparkan pada tahun 60-70-an lelaki gay dikarakteristikan sebagai sosok ramping, bertingkah laku seperti perempuan, dan tidak berotot. Tetapi karena pada tahun 1980-an berkembang penyakit AIDS dan dikonstruksikan bahwa para penderitanya yang berakhir dengan kematian digambarkan memiliki karakteristik yang sama dengan lelaki gay sebelumnya, lelaki gay pada akhirnya berusaha untuk mengubah citranya dengan pergi ke gym dan mengubah bentuk tubuhnya menjadi atletis dan berotot. Bilman melihat bahwa perubahan karakterisasi tubuh ini tidak hanya disebabkan adanya penyakit Aids tetapi juga adanya hegemoni kultur maskulin dalam masyarakat. Saat ini masyarakat menganggap bahwa yang dianggap sebagai laki-laki sejati adalah mereka yang memiliki tubuh ateltis dan berotot yang diidentikkan dengan kekuatan dan kejantanan. Karena para lelaki gay ini tidak dapat melawan peran gender yang disyaratkan masyarakat yang telah berkembang sebelumnya, pada akhirnya mereka berusaha untuk memenuhi penanda-penanda kelaki-lakian agar dapat diterima masyarakat.

Dalam dunia komik, usaha untuk melawan hegemoni seksualitas juga dilakukan. Pada tahun 2002 Marvels Comic Group mengeluarkan komik berjudul the Rawhid's Kid yang didalamnya memiliki karakkter pahlawan gay. Walaupun bukan yang pertama, menurut Lendrum (2005) penerbitan ini telah memberikan dampak yang signifikan dalam wacana seksualitas lain di masyarakat. Kajian Palmer-Mehhta \& Hay (2005) yang menganalisis tema homoseksualitas pada komik Green Lantern menunjukkan bahwa permasalahan seksualitas dalam komik menarik dikaji karena memiliki relasi dan tarik-ulur kekuasaan antara wacana dominan dan minoritas yang terdapat dalam masyarakat. Dari kajian yang dilakukan kita dapat melihat apa yang sebenarnya dikonstruksikan, wacana apa yang dominan, dan nilai-nilai apa yang diusung dalam sebuah masyarakat akan dapat diketahui.

Kajian yang dilakukan dalam tulisan ini menitikberatkan pada unsur bahasa naratif yang menyokong penceritaan komik No Homo karya Apitnobaka. Walaupun demikian, tulisan ini tentu tidak akan mengesampingkan unsur visual yang terdapat dalam komik. Dalam konteks komik Indonesia, salah satu kajian bahasa naratif komik yang menarik telah dilakukan oleh Bonneff (1998). Bonnef mengkaji unsur bahasa naratif dalam komik silat, remaja, dan humor Indonesia yang dalam simpulannya bahwa bahasa Indonesia Jakarta paling banyak mendominasi ragam bahasa komik di Indonesia. Hal ini merefleksikan bahwa Jakarta merupakan pusat imajinasi hasrat terpendam masyarakat Indonesia. Davis (2013) juga pernah melakukan analisis bahasa naratif dalam komik-komik superheroes. Hasil kajiannya menunjukkan meskipun terdapat unsur seksisme dalam visual komik, seksime bahasa tidak ditemukan dalam penggunaan superheroes baik laki-laki maupun perempuan.

\section{HASIL DAN PEMBAHASAN}

Salah satu sumbangan paling penting Foucault dalam perkembangan kajian kebudayaan adalah soal kekuasaan. Kekuasaan bagi Foucault tidak hanya terbatas pada negara/raja terhadap rakyatnya. Baginya kekuasaan tidak hanya bersifat vertikal dari atas ke bawah tetapi menyebar ke berbagai sendi kehidupan. Dover (2016) memaparkan bahwa salah satu aspek penting yang dikemukakan oleh Foucault adalah mengenai kontrol individu. Menggunakan ide bangunan Panoptikon yang dikemukakan oleh Jeremy Bentham, menurut Foucault (1995) kekuasaan dalam dunia modern bersifat kasat mata. Setiap orang dipaksa untuk selalu merasa diawasi sehingga selalu berusaha untuk mengoreksi diri agar sesuai dengan standar norma masyarakat. Kontrol individu ini dikuatkan dengan adanya wacana-wacana ideal yang terdapat dalam masyarakat.

Dalam konteks kajian perempuan, Bartky (2013) mengemukakan bahwa setidaknya ada tiga hal yang selalu membuat perempuan merasa diawasi dan dipaksa untuk selalu menyesuaikan keberadaannya dengan standar masyarakat, terutama yang berkaitan dengan tubuh ideal perempuan. Hal ini dilakukan misalnya melalui penyebaran wacana diet yang mengidealkan tubuh perempuan dengan gambaran ramping, be- 


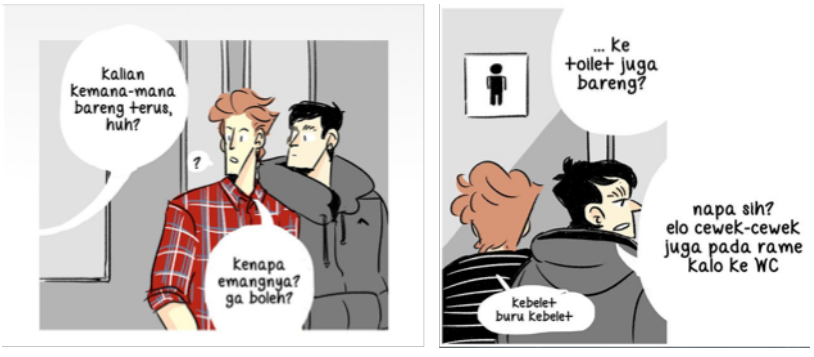

Gambar 1. Panoptikon Muncul Melalui Pembicaraan (Gosip) yang dilakukan Masyarakat

rat badan kecil, berpayudara besar, dan lain-lain. Selain itu, menurut Bartky perempuan diawasi terus menerus untuk menjaga bahasa tubuhnya dibandingkan laki-laki. Terdapat berbagai larangan yang harus dipatuhi perempuan misalnya aturan mengenai cara berjalan, berbicara, ataupun yang lainnya. Jika para perempuan tidak memenuhi wacana ideal ini, perempuan tersebut akan dikategorikan bukan sebagai perempuan ideal tetapi digolongkan sebagai sosok yang $l i$ yan.

Pada teks komik No Homo pengawasan atau Panoptikon ini muncul melalui pembicaraan (gosip) masyarakat mengenai apa yang harus dilakukan oleh seorang laki-laki agar dapat dikategorikan sebagai pria sejati/ideal. Hal ini misalnya dapat dilihat pada gambar 1.

Dari teks di atas dapat dilihat bahwa pembicaraan masyarakat menjadi alat untuk mengontrol individu, khususnya laki-laki. Dalam teks tersebut terlihat bahwa dalam masyarakat patriarkis terdapat beberapa hal menandakan seorang laki-laki dapat digolongkan sebagai sosok yang ideal. Pertama, seorang laki-laki harus menjadi seorang alfa. Hal ini dapat dilihat pada ungkapan "Kalian kemana-mana bareng terus, huh?" Kenapa emangnya? Ga boleh". Kutipan tersebut mengandaikan bahwa seorang laki-laki ideal tidak boleh bergantung pada laki-laki lain. Connel, sebagaimana dikutip oleh Feasey (2008:2) memaparkan bahwa dalam masyarakat terdapat sebuah maskulinitas yang menghegemoni. Maskulinitas tersebut dianggap sebagai preferensi utama setiap laki-laki untuk bersikap dan berperilaku yang ditandai oleh beberapa hal di antaranya heteroseksual, kompetititf, individualis, bersikap agresif, dan lain-lain. Penanda-penanda tersebut dikonstruksikan untuk membedakan posisi laki-laki dan perempuan dalam masyarakat.

Hal ini terbukti dengan kutipan selanjutnya dalam komik ketika tokoh Ditya memberikan pertanyaan: "napa sih? elo cewek-cewek juga pada rame kalo ke WC." Kutipan tersebut menunjukkan adanya oposisi
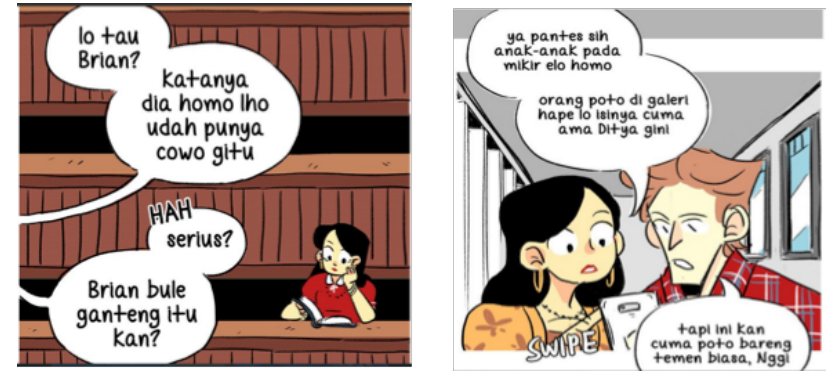

Gambar 2. Angapan Homo yang Tersebar di Masyarakat

biner antara perilaku laki-laki dan perempuan. Laki-laki diidealkan untuk berperilaku individualistis dan perempuan berperilaku komunal. Pemahaman ini diturunkan dari anggapan bahwa laki-laki adalah sosok yang kuat, agresif, dan kompetitif sehingga tidak memerlukan keberadaan orang lain. Adapun perempuan dipandang sebagai sosok yang lemah, pendiam, dan tidak kompetitif sehingga selalu memerlukan perlindungan dari orang lain. Jika ada seorang laki-laki yang justru bersikap sebaliknya maka dirinya dianggap telah melakukan transgresi atau pelanggaran. Hal ini berakibat laki-laki tersebut akan dipandang sebagai bukan laki-laki sejati. Dalam konteks komik No Homo kebiasaan tokoh Brian dan Ditya untuk selalu bersama-sama telah mengundang anggapan masyarakat bahwa mereka berdua adalah seorang homoseksualitas. Hal ini dapat dilihat pada kutipan gambar 2 .

Dalam masyarakat yang menjunjung tinggi heteroseksualitas sebagai orientasi seksual utama, anggapan homoseksualitas merupakan pelanggaran berat. Sharma (2009) menyebutkan bahwa dalam pola pikir normativitas yang menempatkan heteroseksualitas sebagai hal utama setiap gagasan, ide, ataupun hal lain yang dianggap berbeda dengan nilai utama akan jatuh pada penghakiman dan kesalahan. Hal ini disebabkan dalam masyarakat tersebut hanya memiliki dua pola pikir utama yaitu pola pikir sesuatu hal yang normatif (baik menurut norma) dan bukan normatif (tidak baik menurut norma). Pola pikir terse-

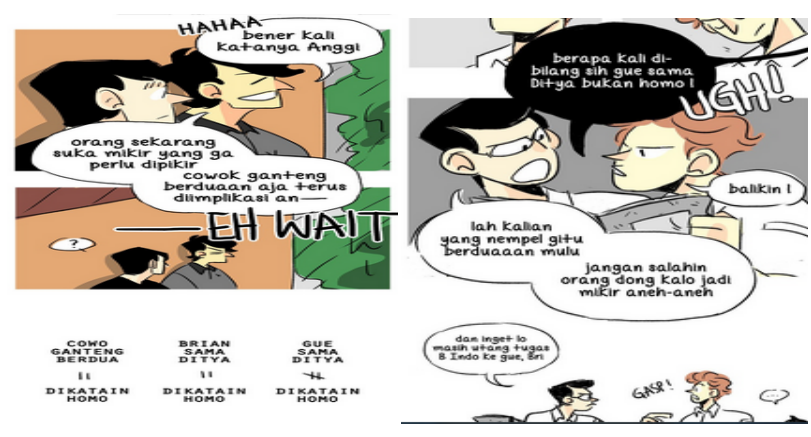

Gambar 3 


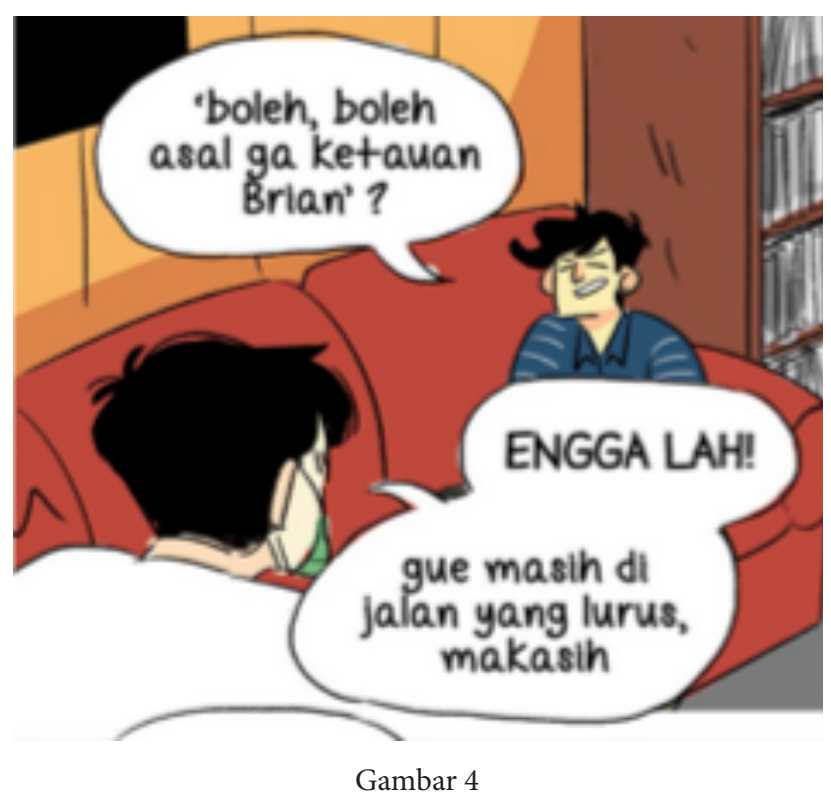

but dapat dilihat pada kutipan gambar 3 .

Dari kutipan gambar 3 dapat dilihat bahwa sebenarnya terdapat penolakan dari tokoh utama untuk digolongkan sebagai seorang homoseksualitas. Selain karena tokoh utama merasa dirinya bukan seorang penyuka sesama jenis, penolakan tersebut disebabkan pola pikir normatif yang muncul di sekitar tokoh yang memosisikan bahwa heteroseksual merupakan orientasi seksual utama dan paling baik. Hal ini dapat dilihat pada kutipan gambar 4 yang mengemukakan bahwa heteroseksual merupakan yang paling baik atau berada "di jalan yang lurus."

Namun demikian, ada sesuatu hal menarik yang dikemukakan oleh kutipan gambar 3. Di dalam teks disebutkan bahwa laki-laki ganteng berdua dianggap sebagai Homo. Tokoh Brian dan Ditya yang digolongkan oleh lingkungan sebagai laki-laki ganteng dikategorikan sebagai homo. Namun ketika Ditya (yang dianggap ganteng) dan temannya (yang dianggap tidak ganteng) justru tidak dipandang homo. Dari hal ini terdapat perbedaan perlakukan terhadap laki-laki seolah-olah hanya laki-laki yang dianggap gantenglah yang dianggap homo. Bilman (2006) mengemukakan di Barat terdapat anggapan bahwa homoseksualitas haruslah memiliki tubuh yang atletis. Namun, dalam konteks komik No Homo penanda tersebut dapat ditambah dengan kondisi paras yang tampan.

Hal ini menjadi menarik apabila melihat latar belakang kedua tokoh utama. Baik Ditya maupun Brian digolongkan sebagai bagian dari kelas menengah-atas. Mereka memiliki pendidikan yang cukup tinggi dan dapat mengakses gaya hidup kelas menengah pada umumnya seperti menggunakan peranti teknolo-

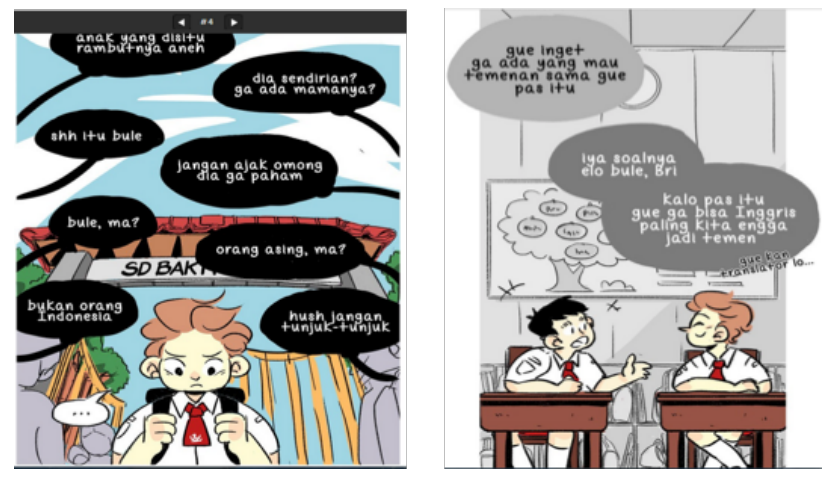

Gambar 5

gi ataupun makan di kafe. Mengacu pada Murtagh (2011) mayoritas representasi filmis dan literer mengenai posisi subjek gay umumnya ditempatkan dalam seting kelompok kelas atas, yang kemudian memperkuat sterotipe bahwa gay Indonesia berasal dari kaum elite. Menurut Murtagh hal ini disebabkan karena pemahaman gay bagi masyarakat Indonesia diperoleh dari media massa yang merepetisi stereotipe bahwa mereka yang memiliki orientasi seksual gay adalah kelompok elite yang lebih jauh lagi bahwa elit (kurang lebih) sama dengan Barat. Pola ini terjadi juga pada komik No Homo yang menggambarkan Brian sebagai sosok asing, bukan Indonesia (gambar 5).

Komik No Homo mungkin secara tidak sadar telah melakukan repetisi pelanggengan stereotipe bahwa mereka yang memiliki orientasi seksual gay biasanya berasal dari Barat. Namun, penelitian yang dilakukan oleh Harding (2008) dan Parker (2014) menunjukkan terdapat sebuah moral panic di kalangan masyarakat Indonesia yang menganggap bahwa kehidupan seksual masyarakat Indonesia terancam oleh invansi Barat. Barat yang dipandang lebih permisif dalam masalah seksual dianggap dapat menciptakan degradasi moral kaum muda Indonesia. Hal ini saya argumentasikan pada akhirnya juga berimplikasi munculnya angapan bahwa orientasi seksual gay berasal dari Barat yang secara tidak sadar terefleksikan dalam komik No Homo melalui tokoh Bryan.

Selain pengulangan stereotipe bahwa mereka yang gay biasanya berasal dari Barat, repetisi yang muncul adalah mereka yang dianggap gay biasanya memiliki permasalahan keluarga. Murtagh (2006) mengemukakan bahwa gambaran kehidupan tokoh-tokoh yang dianggap gay dalam dunia literer Indonesia cenderung tidak baik. Mereka biasanya memiliki permasalahan yang menyebabkan para tokoh pada akhirnya memiliki orientasi seksual berbeda. Dalam komik No Homo hal ini dialami oleh tokoh Ditya yang kedua orang tuanya bercerai sehingga Ditya tidak merasa dekat dengan ayahnya (gambar 6). 

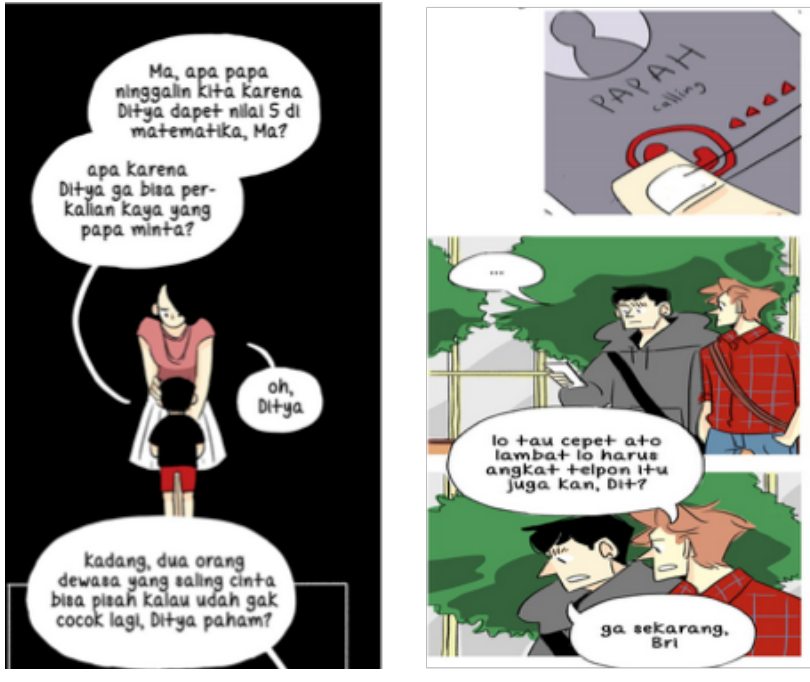

Gambar 6

\section{SIMPULAN}

Dari pembahasan dapat ditarik simpulan bahwa pembicaraan masyarakat (gosip) merupakan alat utama dalam pengonstruksian gender di masyarakat. Gosip berperan sebagai pengawas perilaku seperti apa yang boleh dilakukan laki-laki dan sebaliknya. Gosip berperan sebagai panoptikon dalam mengawasi pelanggengan konstruksi maskulinitas di masyarakat. Selain itu, ditemukan juga salah satu penanda maskulinitas ideal di masyarakat yaitu, laki-laki harus menjadi seorang alfa dan tidak bergantung pada orang lain. Jika seorang laki-laki tidak mampu memenuhi hal tersebut dirinya akan digolongkan bukan laki-laki ideal. Dalam komik No Homo dipandang memiliki orientasi seksual lain yaitu homoseksual yang dianggap tabu dalam masyarakat. Selain itu, komik No Homo merefleksikan dan melanggengkan anggapan bahwa orientasi seksual yang bukan hetero seperti homoseksual bukanlah berasal dari Indonesia. Hal itu dipandang sebagai bagian dari budaya Barat.

\section{DAFTAR RUJUKAN}

Agnes, T. (2016). Pembaca LINE Webtoon Indonesia Terbesar di Dunia. Retrieved from https://m.detik. com/hot/art/d-3274551/pembaca-line-ebtoon-indonesia-terbesar-di-dunia

Bartky, S. L. (2013). Foucault, femininity, and the modernization of patriarchal power. In C. R. Kim \& S. McCann (Eds.), Feminist theory reader: Local and global perspectives (pp. 447-461). New York: Routledge.

Billman, B. N. (2006). The Enfleshment of Masculinity(s): The Maintenance of Hegemonic Masculinity.
Universitas, 2(2), 2-10.

Bonneff, M. (1998). Komik Indonesia. (Y. Hamiyati, Ed.). Jakarta: KPG-Forum Jakarta-Paris.

Davis, R. (2013). Fighting like a girl : Gendered language in superhero comics. Griffith Working Papers in Pragmatics and Intercultural Communication, 6, 28-36.

Dover, J. K. Van. (2016). The Panopticon, the Pinkertons, and the Private Eye. The Lincoln Humanities Journal, 4, 15-26.

Feasey, R. (2008). Masculinity and Popular Television. Edinburgh: Edinburgh University Press.

Foucault, M. (1995). Discipline \& Punish: The Birth of the Prison. New York: Vintage.

Glascock, J., \& Preston-schreck, C. (2004). Gender and Racial Stereotypes in Daily Newspaper Comics : A Time-Honored Tradition? Sex Roles, 51(October), 423-431.

Harding, C. (2008). The Influence of the "Decadent West": Discourses of the Mass Media on Youth Sexuality in Indonesia. Intersections: Gender and Sexuality in Asia and the Pacific, (18).

Hunt, K. N. (2015). THE COMIC BOOK VILLAIN'S BODY: DEVIANT SEXUALITY AND GENDER-TRANSGRESSION. Faculty of the Graduate College of the Oklahoma State University.

Lendrum, R. (2005). Queering Super-Manhood: Superhero Masculinity, Camp and Public Relations as a Textual Framework. IJOCA, SPRING.

Marketeers Editor. (2015). Cara LINE Pikat Tiga Juta Pembaca Komik Online Per Bulan. Retrieved from marketeers.com/cara-line-pikat-tiga-juta-pembaca-komik-online-per-bulan/

Murtagh, B. (2006). Istana kecantikan : the first Indonesian gay movie 1. South East Asia Research, 14(2), 211-230.

Murtagh, B. (2011). Coklat Stroberi : Satu Roman Indonesia dalam Tiga Rasa. Gandrung, 2(1), 45-72.

Palmer-Mehhta, V., \& Hay, K. (2005). A Superhero for Gays? Gay Masculinity and Green Lantern. The Journal of American Culture, 28(4), 390-404.

Parker, L. (2014). The moral panic about the socializing of young people in Minangkabau. Wacana, 1(1), 
$19-40$.

Saraceno, M. J., \& Tambling, R. B. (2013). The Sexy Issue: Visual Expression of Heteronormativity and Gender Identities in Cosmopolitan Magazine. The Qualitative Report, 18.

Sharma, J. (2009). Reflections on the Construction of Heteronormativity. Development, 52(1). Retrieved from http://search.proquest.com/ docview/216910509?accountid-25704

Wibowo, P. H. (2015). Si Jampang Jago Betawi; Kajian Tokoh dalam Komik Ganes TH. Jakarta: Penerbit Buku Kompas. 